\title{
Kelimpahan Populasi Capung Jarum (Zygoptera) di Kawasan Taman Nasional Bogani Nani Wartabone, Sulawesi Utara (Population Abundance of Damselfly (Zygoptera) in Bogani Nani Wartabone National Park, North Sulawesi)
}

\author{
Wakhid $^{2)}$, Roni Koneri ${ }^{1)^{*}}$, Trina Tallei ${ }^{1)}$, Pience V. Maabuat ${ }^{1)}$ \\ 1) Jurusan Biologi FMIPA Universitas Sam Ratulangi \\ ${ }^{2)}$ Alumni Jurusan Biologi FMIPA Universitas Sam Ratulangi \\ *Email korespondensi: ronicaniago@yahoo.com
}

Diterima 4 Juli 2014, diterima untuk dipublikasikan 21 Juli 2014

\begin{abstract}
Abstrak
Capung jarum (Zygoptera) berperan penting bagi keberlangsungan ekosistem.Pada suatu ekosistem, serangga ini berfungsi sebagai agen pengendali hayati dan bioindikator lingkungan.Penelitian ini bertujuan untuk menganalisis kelimpahan capung jarum yang ada pada tiga habitat di Kawasan Taman Nasional Bogani Nani Wartabone, Sulawesi Utara.Pengambilan sampel dilakukan secara purposive random sampling. Koleksi capung jarum menggunakan teknik sweepingmengikuti garis transek sepanjang $500 \mathrm{~m}$ pada setiap tipe habitat. Jumlah transek pada setiap tipe habitat sebanyak 3 garis transek yang dibuat sepanjang aliran sungai.Hasil penelitian didapatkan sebanyak 13 spesies capung jarum yang terdiri dari 4 famili, yaitu Coenagrionidae, Chlorocypidae, Calopterygidae, dan Platycnemididae. Famili yang paling banyak ditemukan jumlah spesiesnya adalah Coenagrionidae, sedangkan yang paling sedikit Platycnemididae. Berdasarkan tipe habitat, jumlah spesies yang paling banyak ditemukan di hutan primer sedangkan yang paling sedikit di hutan sekunder.Kelimpahan capung jarum tertinggi terdapat pada lahan pertanian, sedangkan kelimpahan terendah pada habitat hutan primer

Kata kunci : capung jarum, Taman Nasonal Bogani Nani Wartabone, Sulawesi Utara
\end{abstract}

\begin{abstract}
Damselfly (Zygoptera) plays important roles in the environment and this organism ia able to be used as biocontrol and bioindicator. This research was aimed to analyze the abundance of damselfly that werelocated at three different habitats in Bogani Nani Wartabone National Park, North Sulawesi. The purposive random sampling method was used to collect the samples. Damselflies were taken by using sweeping technique following $500 \mathrm{~m}$ transect line in each habitat. There were three transect lines in each habitat located along the river. The results showed that there were thirteen species from 4 families (Coenagrionidae, Chlorocypidae, Calopterygidae, and Platycnemididae) of damselfly. Most species were members of Coenagrionidae whereas the others werePlatycnemididae Family. Based on the types of habitat, the highest number of species was found in the primary forest, whereas the smallest number was in the secondary forest. Greatest the abundance of damselfly was the largest in the agricultural area and the smallest was in the primary forest.

Keywords: damselfly, Bogani Nani Wartabone National Park, North Sulawesi
\end{abstract}




\section{PENDAHULUAN}

Taman Nasional Bogani Nani Wartabone memiliki fungsi utama bagi pelestarian air dan tanah yang besar sekali sumbangannya terhadap kesejahteraan daerah dan penduduk. Taman Nasional Bogani Nani Wartabone memiliki nilai tinggi guna pelestarian dan penelitian karena merupakan salah satu Taman Nasional daerah hutan tropis terbesar di Asia Tenggara dan memiliki sumber plasma nutfah tertinggi dari semua kawasan suaka di pulau Sulawesi yang memiliki satwa lebih menonjol karena terdiri dari spesies-spesies endemik (Kawuwung 2010).

Permasalahan Taman Nasional Bogani Nani Wartabone yaitu kawasan yang luas menjadi peluang bagi masyarakat untuk membuka kawasan taman (fragmentasi) dijadikan area pertanian, pemukiman, perladangan berpindah, penebangan kayu secara berlebihan, pencurian spesies flora dan fauna, dan pertambangan di dalam kawasan taman. Hal di atas menunjukkan kurangnya pengawasan di Taman Nasional Bogani Nani Wartabone terbukti berkurangnya area Taman Nasional dari 300.000 hektar menjadi 287.115 hektar. Permasalahan di atas menyebabkan menurunnya nilai lingkungan karena berbagai bentuk perusakan hutan yang serius di kawasan Daerah Aliran Sungai Bolango dan Limboto yang telah berakibat menurunnya kualitas air dan mengeringnya Danau Limboto (Kawuwung 2010).

Capung jarum yang merupakan salah satu komponen keanekaragaman hayati banyak terdapat di Kawasan Taman Nasional Bogani Nani Wartabone, Sulawesi Utara. Capung ini memiliki tubuh lebih langsing, lebih kecil dan terbang lambat di bandingkan capung biasa. Ciri lain yaitu memiliki sayap depan dan belakang yang bentuknya sama, keduanya menyempit pada dasarnya dan ketika istirahat dilipatkan diatas tubuh bersama sama atau sedikit melebar (Rohman 2012).

Peran capung jarum bagi keberlangsungan ekosistem adalah indikator pencemaran lingkungan (bioindikator).Pada kondisi perairan sudah tercemar, siklus hidup capung terganggu dan mengakibatkan jumlah populasi menurun.Kelestarian capung perlu dipelihara dengan menjaga keberadaan tempat hidupnya yang sebagian besar berupa perairan (Hidayah 2008).

Capung jarum juga berperan sebagai agen pengendali hayati yaitu sebagai predator hama. Capung jarum turut berperan sebagai musuh alami yang dapat mengurangi populasi hama tanaman pangan (Hidayah 2008). Hal ini menunjukkan posisi penting keberadaan capung jarum dalam keseimbangan ekologi.

Penelitian capung jarum di daerah Taman Nasional Bogani Nani Wartabone pada saat ini masih sedikit dilaporkan.Padahal, informasi tentang keberadaan capung jarum di daerah kawasan Taman Nasional Bogani Nani Wartabone sangat penting mengingat fungsi dari capung jarum tersebut terhadap kesehatan ekosistem hutan baik dari fungsi sebagai bioindikator, dan agen pengendalian hayati (biokontrol).Berdasarkan uraian permasalahan diatas maka perlu dilakukan penelitian tentang kelimpahan populasi capung jarum (Zygoptera) di Kawasan Taman Nasional Bogani Nani Wartabone, Sulawesi Utara.Hasil penelitian ini diharapkan dapat menjadi database tentang kelimpahan capung jarum di kawasan Taman Nasional Bogani Nani Wartabone.

\section{METODOLOGI PENELITIAN}

Penelitian ini dilaksanakan mulai dari Maret sampai April 2014 di 
Kawasan Taman Nasional Bogani Nani Wartabone, Sulawesi Utara.

Bahan dan alat yang digunakan dalam penelitian ini yaitu alkohol $70 \%$, eter, kertas minyak/kertas papilot, kertas label, sterofoam.Peralatan yang dipakai terdiri dari sweepnet (jaring serangga), GPS (merek Garmin), buku identifikasi, kotak koleksi, kamera, jarum pentul, termometer, dan higrometer.Penelitian ini menggunakan metode Purposive Random Sampling.Jadi, penentuan titik pengambilan sampel dilakukan pada lokasi yang terpilih berdasarkan hasil survai. Berdasarkan kondisi hutan, ada tiga tipe habitat hutan yang akan dijadikan sebagai lokasi pengambilan sampel, yaitu:hutan primer, hutan sekunder dan lahan pertanian. Pada masing-masing tipe habitat,empat garis transek dibuat dengan panjang $500 \mathrm{~m}$. Garis transek dibuat di sekitar aliran sungai yang terdapat pada tipe habitat tersebut.

Sampel capung yang diambil dalam penelitian ini adalah capung dewasa (imago). Pengambilan sampel dilakukan pada sepanjang garis transek dengan menggunakan jaring udara. Jaring berbentuk kerucut dengan tinggi $60 \mathrm{~cm}$, diameter $300-380 \mathrm{~cm}$, dan panjang tongkat jaring 1 meter.Pengambilan sampel capung dilakukan setiap bulan selama 3 bulan.Penangkapan dilakukan mulai pukul 09.00 - 15.00 WITA. Hal ini dilakukan karena capung termasuk kelompok serangga yang aktif pada siang hari. Capung yang tertangkap dimasukkan kedalam botol-botol pembunuh yang berisi beberapa kertas tisu dan diisi eter. Setelah capung mati, segera dikeluarkan dari botol pembunuh kemudian dikeringkan di bawah sinar matahari. Hal ini dilakukan agar warna cemerlang Odonata tidak memudar.Kemudian Odonata disimpan dalam amplop-amplop kertas segitiga yang berukuran $30 \times 20 \mathrm{~cm}$ dengan posisi sayap terlipat diatas tubuh.Setiap amplop disimpan satu capung (Ansori, 2009).

Sampel kemudian diidentifikasi di Laboratorium Ekologi dan Biokonservasi, Jurusan Biologi, FMIPA Unsrat dan dihitung jumlah individunya.Proses identifikasi dilakukan berdasarkan ciri morfologi eksternal dengan menggunakan buku Theischinger (2009), Borror et al. (1996), Watson and Farrel (1991), Miller (1995), Orr (2003), Kalkman dan Orr (2013), Wilson (1995) dan Lieftinck (1949).

\section{HASIL DAN PEMBAHASAN}

Capung jarum yang ditemukan dalam penelitian ini terdiri atas 13 spesies, 485 individu yang termasuk dalam 4 famili yaitu Coenagrionidae (61,44\%), Chlorocypidae (25,77\%), Calopterygidae $\quad(12,37 \%), \quad$ dan Platycnemididae $(0,41 \%)$. Famili yang paling banyak ditemukan yaitu Coenagrionidae sebanyak 6 spesies $(61,44 \%)$ sedangkan famili yang paling sedikit yaitu Platycnemididae dengan jumlah 1 spesies $(0,41 \%)$ (Gambar 1$)$. Famili Coenagrionidae terdiri dari 6 spesies, Famili Chlorocypidae sebanyak 4 spesies, Famili Calopterygidae 2 spesies dan famili Platycnemididae hanya terdiri dari 1 spesies (Tabel 1). Spesies capung jarum yang memiliki kelimpahan paling banyak ditemukan yaitu Agriocnemis rubescens 146 individu (30,10\%), Pseudagrion pilidorsum 73 individu (15,05\%) dan Neurobasis australis 59 individu (12,16\%). Spesies capung jarum yang paling sedikit ditemukan adalah Mantronoides cyaneipennissatu individu (0,21\%), Lochmaeocnemis malacodora 2 individu $(0,41 \%)$ dan Teinobasis laidlawi 3 individu (0,62\%) (Tabel 1). Coenagrionidae melimpah ditemukan karena famili ini merupakan 
famili terbesar jumlahnya dalam Subordo Zygoptera dan penyebarannya merata di seluruh dunia (Orr 2003). Coenagrionidae merupakan salah satu famili capung di mana sebagian besar spesiesnya ditemukan di habitat air yang tidak mengalir (Kalkman dan Orr 2013), sehingga Coenagrionidae dapat hidup di berbagai tipe habitat baik pada habitat perairan mengalir dan tidak mengalir.Kemampuan adaptasi yang tinggi dari Coenagrionidae ini menyebabkan tingginya jumlah spesies yang ditemukan berbagai habitat.

Lokasi penelitian yang memiliki kelimpahan individu tertinggi yaitu pada habitat pertanian, dengan jumlah individu 195 individu (40,21\%), selanjutnya pada habitat hutan sekunder dengan jumlah individu 149 individu (30,72\%). Habitat hutan primer memiliki kelimpahan individu lebih sedikit dibanding dengan habitat lain sebanyak 141 individu (29,07\%) (Tabel 1). Kelimpahan capung jarum yang tingi pada habitat pertanian disebabkan tingginya intensitas cahaya dan kurangnya penutupan vegetasi tumbuhan di sekitar sungai pada habitat pertanian.Capung jarum mempunyai kebiasaan berjemur di bawah sinar matahari untuk menghangatkan tubuhnya dan untuk mempekuat otototot sayap untuk terbang (Susanti 1998), tingginya intensitas cahaya dan kurangnya penutupan vegetasi pada habitat pertanian sehingga jumlah capung jarum yang ditemukan melimpah.

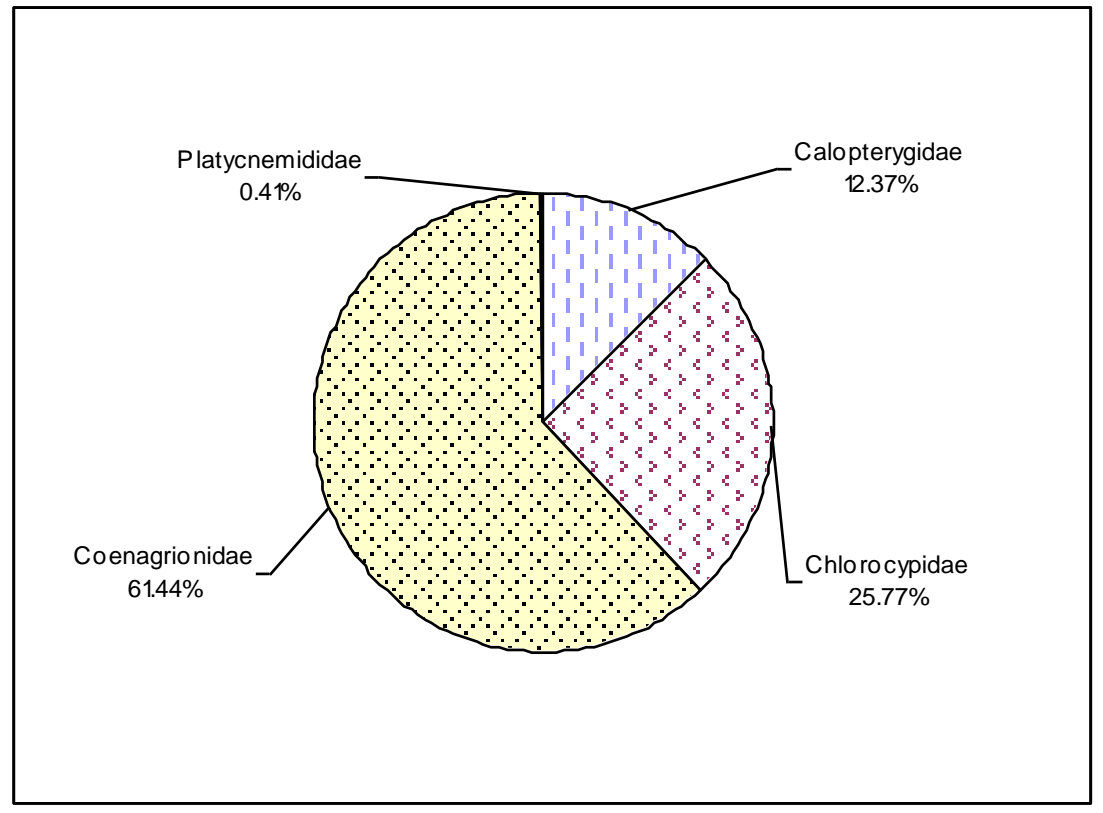

Gambar 1. Famili capung jarum yang ditemukan pada tiga tipe habitat 
Tabel 1. Jumlah famili dan spesies capung jarum yang ditemukan pada tiga tipe habitat di kawasan Taman Nasional Bogani Nani Wartabone, Sulawesi Utara

\begin{tabular}{|c|c|c|c|c|c|c|c|c|c|}
\hline \multirow{2}{*}{ No } & \multirow{2}{*}{ Famili/Spesies } & \multicolumn{2}{|c|}{ Htn Primer } & \multicolumn{2}{|c|}{ Htn Sekunder } & \multicolumn{2}{|c|}{ Lahan Pertanian } & \multicolumn{2}{|c|}{ Total } \\
\hline & & Jumlah & $\%$ & Jumlah & $\%$ & Jumlah & $\%$ & Jumlah & $\%$ \\
\hline $\mathbf{I}$ & Calopterygidae & & & & & & & & \\
\hline 1 & Mantronoides cyaneipennis & 1.00 & 0.21 & 0.00 & 0.00 & 0.00 & 0.00 & 1.00 & 0.21 \\
\hline 2 & Neurobasis australis & 53.00 & 10.93 & 0.00 & 0.00 & 6.00 & 1.24 & 59.00 & 12.16 \\
\hline II & Chlorocypidae & & & & & & & & \\
\hline 3 & Libellago aurantiaca & 5.00 & 1.03 & 3.00 & 0.62 & 10.00 & 2.06 & 18.00 & 3.71 \\
\hline 4 & Libellago hyalina & 6.00 & 1.24 & 0.00 & 0.00 & 0.00 & 0.00 & 6.00 & 1.24 \\
\hline 5 & Libellago phaeton & 0.00 & 0.00 & 25.00 & 5.15 & 28.00 & 5.77 & 53.00 & 10.93 \\
\hline 6 & Rhinocypha humeralis & 48.00 & 9.90 & 0.00 & 0.00 & 0.00 & 0.00 & 48.00 & 9.90 \\
\hline III & Coenagrionidae & & & & & & & & \\
\hline 7 & Agriocnemis femina & 0.00 & 0.00 & 9.00 & 1.86 & 45.00 & 9.28 & 54.00 & 11.13 \\
\hline 8 & Agriocnemis rubescens & 0.00 & 0.00 & 100.00 & 20.62 & 46.00 & 9.48 & 146.00 & 30.10 \\
\hline 9 & Amphicnemis bebar & 6.00 & 1.24 & 0.00 & 0.00 & 0.00 & 0.00 & 6.00 & 1.24 \\
\hline 10 & Archibasis melanocyana & 4.00 & 0.82 & 11.00 & 2.27 & 1.00 & 0.21 & 16.00 & 3.30 \\
\hline 11 & Pseudagrion pilidorsum & 13.00 & 2.68 & 1.00 & 0.21 & 59.00 & 12.16 & 73.00 & 15.05 \\
\hline 12 & Teinobasis laidlawi & 3.00 & 0.62 & 0.00 & 0.00 & 0.00 & 0.00 & 3.00 & 0.62 \\
\hline IV & Platycnemididae & & & & & & & & \\
\hline 13 & Lochmaeocnemis malacodora & 2.00 & 0.41 & 0.00 & 0.00 & 0.00 & 0.00 & 2.00 & 0.41 \\
\hline & $\begin{array}{l}\text { Total } \\
\end{array}$ & 141.00 & 29.07 & 149.00 & 30.72 & 195.00 & 40.21 & 485.00 & 100.00 \\
\hline
\end{tabular}

Frekuensi capung jarum yang ditemukan pada tiga habitat berbedabeda. Beberapa spesies ditemukan dengan frekuensi yang rendah dan hanya ditemukan pada salah satu habitat sebanyak 6 spesies yaitu $M$. cyaneipennis, T. laidlawi, Libellago hyalina, Rhinocypha humeralis, Amphicnemis bebar, dan $L$. malacodora. Capung jarum dengan frekuensi yang rendah dan distribusinya terbatas hanya pada satu tipe habitat bersifat peka terhadap perubahan habitat. Capung jarum tidak akan ditemukan pada hutan yang telah mengalami gangguan atau hutan yang telah mengalami alih fungsi (Dolny et al. 2011).

Distribusi dari capung jarum pada ketiga habitat sangat bervariasi. Spesies capung jarum dengan distribusinya yang merata atau ditemukan pada ketiga habitat sebanyak 3 spesies yaitu Libellago aurantiaca, Archibasis melanocyana dan P.pruinosum (Tabel 1). Spesies capung jarum yang hanya ditemukan di habitat hutan primer dan tidak ditemukan di habitat lainnya sebanyak 6 spesies yaitu M. cyaneipennis, $T$. laidlawi, Libellago hyalina, Rhinocypha humeralis, Amphicnemis bebar, dan L.malacodora. Menurut Dolny et al. (2011), capung jarum tidak akan ditemukan pada hutan yang telah mengalami gangguan atau hutan yang telah mengalami alih fungsi, sehingga keberadaannya dapat mengindikasikan kondisi suatu hutan sebagai hutan yang masih sehat atau telah mengalami kerusakan. Keenam spesies capung jarum yang hanya ditemukan di habitat hutan primer dapat dijadikan salah satu penentu kualitas kesehatan hutan (bioindikator).

\section{KESIMPULAN}

Jumlah spesies capung jarum yang ditemukan di kawasan Taman Nasional Bogani Nani Wartabone sebanyak 485 individu dari 13 spesies yang terdiri dari 4 famili. Famili yang 
paling banyak ditemukan yaitu famili Coenagrionide, sedangkan yang paling sedikit adalah Famili Platycnemididae. Kelimpahan spesies capung jarum tertinggi ada pada $A$. rubescens, $P$. pilidorsum dan $N$. australis. Spesies capung jarum yang kelimpahannya paling sedikit ditemukan adalah $M$. cyaneipennis, $L$. malacodora dan $T$. laidlawi.

\section{DAFTAR PUSTAKA}

Ansori I (2009) Kelimpahan dan dinamika populasi Odonata berdasarkan hubungannya dengan fenologi padi di beberapa persawahan sekitar Bandung, Jawa Barat. Jurnal Exacta 7: 69-75

Borror DJ, Triplehorn CA, Johnson NF (1996) Pengenalan pelajaran serangga. Edisi Keenam. Gadjah Mada University Press. Yogyakarta

Dolný A, Bárta D, Lhota S, Rusdianto, Drozd P (2011) Dragonflies (Odonata) in the Bornean rain forest as indicators of changes in biodiversity resulting from forest modification and destruction. Tropical Zoology 24: 63-86

Hidayah SNI (2008) Keanekaragaman dan aktivitas capung (Ordo: Odonata) di Kebun Raya Bogor. Skripsi..Institut Pertanian Bogor. Bogor

Kalkman V, Orr AG (2013) Field guide to the damselflies of New Guinea. Scholma Druk BV Bedum

Kawuwung FR (2010) Potensi Taman Nasional Bogani Nani Wartabone, permasalahan dan konservasi pada tingkat pengembangan dan pengawasan. Skripsi. Universitas Negeri Manado. Manado
Lieeftinck MA (1949) The dragonflies (Odonata) of New Guinea and Neighbouring Islands. Part VII. Results of Third Archbold Expedition 1938-1939 and the Le Roux Expedition 1939 to Netherlands New Guinea (II.Zygoptera). Nova Guinea New Series 5: 1-271

Magurran AE (1988) Ecological diversity and its measurements. Croom Helm Limited. London

Miller PL (1995) Dragonflies.The Queen's College.Oxford

Orr AG (2003) A guide to the dragonflies of Borneo their identification and biology. Natural History Publications (Borneo). Kinabalu

Rohman A (2012) Keanekaragaman jenis dan distribusi capung (Odonata) di Kawasan Kars Gunung Sewu, Kecamatan Pracimantoro, Kabupaten Wonogiri, Jawa Tengah. Skripsi. Universitas Negeri Yogyakarta. Yogyakarta

Shanty S (1998) Seri panduan lapangan mengenal capung. Pusat Penelitian dan Pengembangan Biologi - LIPI. Bogor

Statsoft (2001) Stastistica for windows, 6.0. Statsoft Inc. Tulsa

Susetyo B (2010) Statistika untuk analisis data penelitian. Refika Aditama. Bandung

Theischinger G (2009) Identification guide to the Australian Odonata. Department of Environment, Climate Change And Water NSW. Sidney

Watson J, Farrel A (1991) The Australian dragonflies a guide to the identification and habitats of Australian Odonata. CSIRO. Australia. 
Wilson KDP (1995) Hongkong dragonflies. Urban Council. Hongkong. 